\title{
Development and Application of Computer Virtual Reality Technology Zhipeng $\mathrm{Hu}^{1, \mathrm{a}}$ and Meng $\mathrm{Xu}^{2, \mathrm{~b}}$ * \\ ${ }^{1}$ Information Technology and Media College of Beihua University, Jilin 132013, China \\ ${ }^{2}$ Information Technology and Media College of Beihua University, Jilin 132013, China \\ ahuzhipengstudy@163.com, ${ }^{\text {b3066567@qq.com }}$
}

\section{Keywords: Virtual reality technology ; Teaching software}

\begin{abstract}
This paper puts forward the "moot court teaching software" developed by virtual reality technology, and constructs "moot court" virtual laboratory, in order to solve the problem of insufficient number of "moot court", so that each student is involved in the practice teaching, and the teaching effect is good.
\end{abstract}

\section{Introduction}

"Simulation of court" is an important course in the legal practice of law professional teaching, the teaching method is a combination of theoretical and practice teaching in law education or teaching mode, is under the guidance of teachers, students played by different judges, prosecutors, lawyers and the parties and other participants in the proceedings of litigation role in the simulation under the auspices of the judges, by simulation judges in accordance with strict legal procedures in the court of the virtual real or virtual case simulation trial of a kind of teaching activity [1]. All colleges and universities with law major, whether undergraduate or specialist, must carry out moot court teaching activities [2]. Because of this, most colleges and universities in China (including undergraduate and specialist, including more than 400 undergraduate), most of them pay more attention to the construction of moot court, but also pay more attention to the simulation of the teaching of the court more than 600 . However, due to the limited number of "moot court" (up to 3-5), it can not meet the needs of each student to participate in the experimental teaching, only one student can participate in the practice, and the other students carry out the mode of observation, and the teaching effect is poor. On the basis of investigation, analysis and demonstration, our school solved the problem of insufficient number of moot court by using modern educational technology, and let every student participate in the practice teaching, and the teaching effect is good.

\section{Virtual Reality Technology}

The Definition of Virtual Reality Technology. Virtual reality technology is a new research field on the basis of the continuous development of computer technology. It is another major breakthrough in computer applications after multimedia technology [3]. Is an emerging technology discipline, it mainly based on computer technology, integration of 3D computer graphics technology, simulation technology, sensor technology and human-machine interface technology, display technology, servo technology, to generate a realistic 3D world, a user can take as their main points, browse and interact with the virtual world object [4].

The Characteristics of Virtual Reality Technology. Immersive virtual environment is that users can immerse in computer generated and users into the virtual scene in computer generated, users have "personally on the scene" feeling in the virtual scene. What it sees, hears, smells, touches, is exactly like what it feels in the real world. It is the core of virtual reality system.

Interactivity refers to the ability of users to interact with objects in a virtual scene. It is the key factor of man-machine harmony. When users enter the virtual environment, they interact with the environment of multidimensional information through a variety of sensors. The user can do the necessary operation, and the corresponding response in the virtual environment is also the same as the real. 
Imagination is defined by the user is immersed in the "virtual real environment", the interaction with the virtual environment, get familiar with the sensibility and rationality from qualitative and quantitative integrated environment, which can deepen the concept of new generation, germination, leap on understanding. Therefore, virtual reality is not only an interface between users and terminals, but also allows users to immerse themselves in this environment to acquire new knowledge, improve perceptual and rational familiarity, and thus generate new ideas. The idea results are input into the system, and the system will display the processed state in real time or feedback it to the user through the sensing device. Thus, it is a process of learning, creation, re learning and recreation, so it can be said that virtual reality is the activity of enlightening creative thinking.

The Application of Virtual Reality Technology. Virtual reality technology can be applied to military, modeling and simulation, visualization of scientific computing, education and training, medicine, art and entertainment, and so on. In particular, it has had a profound impact on education, changed some of the previous teaching concepts and teaching mode, which constitutes the denial and Deconstruction of the reality of some traditional teaching models. Virtual reality technology presents possibilities of the development of educational technology, break through the narrow traditional teaching mode, broaden the developing space of the existing teaching method, so as to establish the rationality, transcendence and innovation of the non-reality, provides a new space for teaching innovation. Virtual reality technology can provide all kinds of information of visual, auditory and tactile, participants interact with the virtual environment in a natural way, to participate in the development of personally on the scene event in the virtual environment, so as to maximize the control and operation of the entire event of freedom. This multi-dimensional interactive information environment will provide participants with the most intuitive and effective way to master a new knowledge and new skills to provide an unprecedented new way.

\section{Moot Court Teaching Software}

The Technology of Developing Moot Court Teaching Software. "The moot court teaching software" to the court trial layout for reference, the use of virtual reality technology, integration of 3D simulation technology, and give full consideration and analysis of civil and criminal (public prosecution and private prosecution), the administrative case trial layout, a true representation of the real trial, and has real-time dialogue function. By using the object-oriented design method, the abstract and complex legal theory and practical knowledge are closely integrated. The system is based on B/S architecture and .NET technology development, programming language ASP.NET, background database SQL Server 2000.

The main technologies are:

3D simulation technology

The 3D virtual simulation is the use of 3D modeling technology, three-dimensional scene construction of the real world and drive the 3D scene through a certain software environment, in response to user input, make the corresponding response according to different user action, and displayed in the 3D environment. With the layout of court trial as the reference, the virtual reality technology, the fusion of three-dimensional simulation technology, and full consideration and analysis of civil, criminal (public prosecution, private prosecution), administrative case layout of the trial, the real reappearance of the trial real scene.

NET Technology

Web consists of simple web services from static to dynamic web service, service website can interact to perform some complex steps, these services may require a Web service call other Web services, and as a traditional software program that executes the command. This requires the integration and other services, the need for multiple services can work together seamlessly, need to be able to create applications with device independent, some steps can easily coordinate the various services on the network, to create a new user oriented service.

Microsoft Corp launched the.NET system technology is just to meet this demand. .NET takes Internet itself as the basis for building a new generation of operating systems, and extends the design ideas of Internet and operating systems, enabling developers to create device independent applications and easily implement Internet connections. 
.NET technology is a development environment based on Microsoft XML Web services platform launched by Microsoft Corp, which consists of a set of software components for building Web services applications and Windows desktop applications, including .NET framework (Framework), .NET developer tools and ASP.NET

Web 2.0 Technology

A knowledge base is embedded in the system. Teachers and students are not only the browser of the knowledge base, but also the creator of the knowledge base. Makers of the so-called knowledge base is that every student, teachers are not only the readers, but also become the knowledge base of the author, from a simple "reading" to "writing" and "common development" development, from passively receiving information for the knowledge base to take the initiative to create the knowledge base of information development, and thus more humanization and sharing.

The Function Of Moot Court Teaching Software. According to the characteristics of information aided instruction, the system adopts three level management structure model, which consists of administrator end system, teacher end system and student end system [5]. The operation interface is independent, data sharing and transmission are realized, and the management objectives of monitoring, communication and collaboration are realized. The main functions of each system are as follows:

Administrator system administrator's main task is to maintain the operation of the system and the teacher's information to add, delete, modify.

The teacher is the organizer and end system of teachers management of the experimental teaching, the experimental class management, experiment content, experiment issued the students assigned to roles, the announcement, to provide a reference case, build the experimental environment, experimental configuration parameters, control experiment, and test results verify the view.

Student end system students are the active participants in experimental teaching. According to the role assigned by teachers, the court experiments corresponding to their respective roles are completed. The experiment is divided into three stages: preparation, hearing, and ending. In the experiment, the experimental process and results were summarized, summed up the operation and information set, with test report form for upload, teachers' evaluation. At the same time can also own information such as civil cases, public prosecution, public prosecution and private prosecution cases of incidental civil litigation, prosecution incidental civil litigation and administrative cases submitted by the teachers review, after approval, you can join the case library, as a basis to carry out experiments. Online teachers can also participate in the examination and online discussion.

\section{Effect Analysis}

Our school through virtual reality technology to develop the "moot court teaching software installation, construction simulation court of virtual laboratory, solve the" simulation of court "problem of insufficient quantity, so that each student to participate in the practice teaching, the teaching effect is obvious.

(1) It solves the problem that the number of moot court is not enough, so that every student is active, from the original spectator into a positive participant. The software uses 3D virtual reality scene to simulate the court session, increase interactivity, let the court no longer become boring, stimulate students' enthusiasm and interest in learning, improve the learning efficiency and teaching effect.

(2) The moot court teaching software installation to the school network center server, not affected by time and space, students can complete the experiment in the room of dormitory and school, but also as a case, let many groups of students at the same time trial, in order to test the students learn the knowledge of the understanding of the situation.

(3) Using the characteristics of computer mass storage, it provides online inquiry of laws, regulations and judicial interpretations, so that students can consult at any time during the trial process, and they can also be used as after-school queries. And it provides a large number of evidence base, students can collect evidence according to the needs of the case, so as to improve the ability of students to use evidence.

(4) There are many types of cases, such as civil, criminal, administrative, summary procedure, general procedure and other types of cases. The real imitation of the actual trial in all aspects of the procedure, so that students are better familiar with the court trial activities. In addition, the legal clinic service for the 
legal profession enables the students to do simulation exercises before the case of proxy litigation, so that the students can be more fully prepared in the court trial.

(5) By the computer to guide students to the production of legal instruments (indictment, summons, notice of acceptance, responding to the notice, the members of the collegial panel, confirmation of receipt, court records, collegiate records) and judgment (judgment, mediation, ruling). This makes the students more standardized and quick writing of various documents. According to the actual court case binding, students complete the written record after the experiment is completed, as an experimental report for teacher assessment score.

(6) The teacher doesn't have to watch the student court at the moot court. After the completion of the trial, the teacher only needs to see the legal documents and the whole court performance of the students when they play different roles in the background, which can be scored according to the performance of the students in the court session.

(7) The system provides a real-time interactive platform for teachers and students, which helps teachers better guide students, and also help students communicate with each other.

(8) The system incorporates a comprehensive, rich knowledge base system, including laws and regulations, arbitration documents, judicial documents, a classic case of legal knowledge, not only provides a platform for students to broaden their knowledge level, but also conducive to improving the ability of analysis and solve the problem of judicial practice. May also allow teachers and students to their own information such as civil cases, public prosecution, public prosecution and private prosecution cases of incidental civil litigation, prosecution incidental civil litigation cases and administrative cases submitted to the audit, through the audit, you can join in the knowledge base, as the foundation to carry out the experiment.

\section{Conclusion}

The legal knowledge obtained has three levels: the first level, of course, is the understanding of the law, the law on how it is, what kind of a thing; the second level is the use of the law; the last level, in addition to understanding the application of the law, should know what kind of law is to adapt to the reality of the times and society, and how to make the law modernization and socialization. The above three levels of teaching methods should be different, the latter two levels, in addition to the teaching of teachers, more students are independent thinking, and through practice [7]. Therefore, colleges and universities should strengthen the construction of practice teaching, seek the combination point of modern education technology and law teaching, make up for the lack of hardware facilities and traditional teaching, and constantly improve the quality of education and teaching.

\section{Acknowledgments}

This work is supported by the Teaching Research Project of the College of Beihua University of Jilin Province (No. XJQN2017016)

\section{References}

[1] Monika Dávideková,Michal Mjartan,Michal Greguš. Utilization of Virtual Reality in Education of Employees in Slovakia[J]. Procedia Computer Science,2017,113:.

[2] Jih-Hsuan Tammy Lin. Fear in virtual reality (VR): Fear elements, coping reactions, immediate and next-day fright responses toward a survival horror zombie virtual reality game[J]. Computers in Human Behavior,2017,72:.

[3] Brenda K. Wiederhold,Giuseppe Riva,Sandra Poeschl,Nicola Doering. The German VR Simulation Realism Scale - Psychometric Construction for Virtual Reality Applications with Virtual Humans[J]. Studies in Health Technology and Informatics,2013,191:.

[4] Brenda K. Wiederhold,Giuseppe Riva,Sandra Poeschl,Nicola Doering. The German VR Simulation Realism Scale - Psychometric Construction for Virtual Reality Applications with Virtual 
Humans[M].IOS Press:2013.

[5] Xianwei Huang,Fazel Naghdy,Golshah Naghdy,Haiping Du,Catherine Todd. The Combined Effects of Adaptive Control and Virtual Reality on Robot Assisted Fine Hand Motion Rehabilitation in Chronic Stroke Patients: a Case Study[J]. Journal of Stroke and Cerebrovascular Diseases, 2017,: .

[6] Amine Chellali, Helena Mentis,Amie Miller, Woojin Ahn, Venkata S. Arikatla, Ganesh Sankaranarayanan, Suvranu De, Steven D. Schwaitzberg,Caroline G.L. Cao. Achieving Interface and Environment Fidelity in the Virtual Basic Laparoscopic Surgical Trainer[J]. International Journal of Human - Computer Studies, 2016,:

[7] Yeshwanth Pulijala, Minhua Ma, Ashraf Ayoub. VR Surgery: Interactive Virtual Reality Application for Training Oral and Maxillofacial Surgeons using Oculus Rift and Leap Motion[M]. Springer International Publishing:2017. 